International Journal of Modeling, Simulation,

and Scientific Computing

Vol. 8, No. 4 (2017) 1799001 (9 pages)

(C) World Scientific Publishing Company

DOI: $10.1142 /$ S179396231799001X

\title{
Author index \\ Volume 8 (2017)
}

Chen, Y.-C., Gao, X.-B., Gao, M. and Lv, H.-M.,

Aerodynamic characteristic of a canard guided rocket $\quad 1$ (2017) 1750001

Gao, X.-B., see Chen, Y.-C.

1 (2017) 1750001

Gao, M., see Chen, Y.-C.

1 (2017) 1750001

Lv, H.-M., see Chen, Y.-C.

1 (2017) 1750001

Nyoni, B., Hlabano-Moyo, B. M. and Chimwe, C., Using a simulation software to perform energy and exergy analyses of the sulfur-iodine thermochemical process

1 (2017) 1750002

Hlabano-Moyo, B. M., see Nyoni, B.

Chimwe, C., see Nyoni, B.

1 (2017) 1750002

1 (2017) 1750002

Suryanarayana, G. and Dhuli, R., Edge preserving super-resolution algorithm using multi-stage cascaded joint bilateral filter

1 (2017) 1750003

Dhuli, R., see Suryanarayana, G.

1 (2017) 1750003

Zhu, Z.-X., Yin, Y. and Movania, M. M., A novel parallel algorithm for computing the mooring line based on lumped-mass method

1 (2017) 1750004

Yin, Y., see Zhu, Z.-X.

1 (2017) 1750004

Movania, M. M., see Zhu, Z.-X.

1 (2017) 1750004

Nacher, J. C. and Ochiai, T., Analytical solution for the size of the minimum dominating set in complex networks

1 (2017) 1750005

Ochiai, T., see Nacher, J. C.

1 (2017) 1750005

Mohamed, I., El-Henawy, I. and El-Din, R. Z., An early discharge approach for managing hospital capacity

1 (2017) 1750006

El-Henawy, I., see Mohamed, I.

1 (2017) 1750006

El-Din, R. Z., see Mohamed, I.

1 (2017) 1750006

Dai, S., Kang, Y., Zhu, G., Zheng, X. and Wen, Y., Numerical simulation of air purging conditions during steel sheet temper rolling process

1 (2017) 1750007

Kang, Y., see Dai, S.

1 (2017) 1750007

Zhu, G., see Dai, S.

1 (2017) 1750007

Zheng, X., see Dai, S.

1 (2017) 1750007

Wen, Y., see Dai, S.

1 (2017) 1750007 
Chen, Z., Zhu, Y., Di, Y. and Feng, S., Optimization of virtual machine placement based on constrained immune memory and immunodominance clone in IaaS cloud mode equipment training

Zhu, Y., see Chen, Z.

1 (2017) 1750008

1 (2017) 1750008

Di, Y., see Chen, Z.

Feng, S., see Chen, Z.

1 (2017) 1750008

1 (2017) 1750008

Zamula, A. and Kavun, S., Complex systems modeling with intelligent control elements

1 (2017) 1750009

Kavun, S., see Zamula, A.

1 (2017) 1750009

Vinoth, J. and Rose, J. B. R., Dynamic stability characterization of re-entry modules at hypersonic mach numbers

1 (2017) 1750010

Rose, J. B. R., see Vinoth, J.

1 (2017) 1750010

He, Z., Deng, T. and Xu, X., Vibration performance discrete optimization of a gear system featuring confluence transmission used in marine gearbox

1 (2017) 1750011

Deng, T., see He, Z.

$\mathrm{Xu}, \mathrm{X}$., see He, Z.

1 (2017) 1750011

1 (2017) 1750011

Hou, Y., Feng, R., Liu, Y., Li, H. and Gao, W., A MFE method combined with L1-approximation for a nonlinear time-fractional coupled diffusion system

1 (2017) 1750012

Feng, R., see Hou, Y.

Liu, Y., see Hou, Y.

1 (2017) 1750012

1 (2017) 1750012

Li, H., see Hou, Y.

1 (2017) 1750012

1 (2017) 1750012

Gao, W., see Hou, Y.

Krivovichev, G. V., On the stability of lattice boltzmann equations for one-dimensional diffusion equation

1 (2017) 1750013

Alagoz, B. B., Alisoy, H. Z., Koseoglu, M. and Alagoz, S., Modeling and analysis of dielectric materials by using gradient-descent optimization method

1 (2017) 1750014

Alisoy, H. Z., see Alagoz, B. B.

1 (2017) 1750014

1 (2017) 1750014

1 (2017) 1750014

Alagoz, S., see Alagoz, B. B.

Jarrah, A., Haddad, B., Al-Jarrah, M. A. and Obeidat, M.

B., Optimized parallel architecture of evolutionary neural network for mass spectrometry data processing

Haddad, B., see Jarrah, A.

1 (2017) 1750016

1 (2017) 1750016

1 (2017) 1750016

Al-Jarrah, M. A., see Jarrah, A.

1 (2017) 1750016

Li, S. C., Li, X. G., Cao, J. J. and Li, W. B., High-order numerical method for the derivative nonlinear Schrödinger equation

1 (2017) 1750017 
Li, X. G., see Li, S. C.

1 (2017) 1750017

Cao, J. J., see Li, S. C.

1 (2017) 1750017

Li, W. B., see Li, S. C.

1 (2017) 1750017

Yaghobi Moghaddam, M., Shafaei Tonkaboni, S. Z.,

Noaparast, M. and Doulati Ardejani, F., A mathematical model to simulate heap (bio)-leaching process: An exact conceptual model, Homotopy theory and comparative insights with conventional methods

1 (2017) 1750018

1 (2017) 1750018

1 (2017) 1750018

Noaparast, M., see Yaghobi Moghaddam, M.

1 (2017) 1750018

Durst, P. J., Anderson, D. T. and Bethel, C. L., A historical review of the development of verification and validation theories for simulation models

Anderson, D. T., see Durst, P. J.

2 (2017) 1730001

2 (2017) 1730001

Bethel, C. L., see Durst, P. J.

2 (2017) 1730001

$\mathrm{Wu}$, J., The key technology research for integrated simulation of multi-disciplinary complex product system

Li, B. H., Song, X., Zhang, L., Liu, J., Chi, P., Lin, T., Zhang, X., Laili, Y., Tao, F. and Li, T., CoSMSOL:

Complex system modeling, simulation and optimization language

2 (2017) 1741002

Song, X., see Li, B. H.

2 (2017) 1741002

Zhang, L., see Li, B. H.

2 (2017) 1741002

2 (2017) 1741002

2 (2017) 1741002

Chi, P., see Li, B. H.

2 (2017) 1741002

Lin, T., see Li, B. H.

2 (2017) 1741002

2 (2017) 1741002

Laili, Y., see Li, B. H.

2 (2017) 1741002

2 (2017) 1741002

Li, T., see Li, B. H.

Zhao, J., Liu, Y., Qu, Y., Bian, F. and Ban, Y., Model and simulation of four-wheeled robot based on Mecanum wheel

2 (2017) 1750015

Liu, Y., see Zhao, J.

2 (2017) 1750015

Qu, Y., see Zhao, J.

2 (2017) 1750015

2 (2017) 1750015

2 (2017) 1750015

Ban, Y., see Zhao, J.

Ma, L., Chen, B., Qiu, S., Li, Z. and Qiu, X., Agent-based modeling of emergency evacuation in a railway station square under sarin terrorist attack

2 (2017) 1750022

Chen, B., see Ma, L.

2 (2017) 1750022 
Qiu, S., see Ma, L.

2 (2017) 1750022

Li, Z., see Ma, L.

2 (2017) 1750022

Qiu, X., see Ma, L.

2 (2017) 1750022

Meng, D., Yao, Y.-P. and Yao, F., An enhanced dead reckoning algorithm with hybrid extrapolation models (AisaSim 2016)

Yao, Y.-P., see Meng, D.

2 (2017) 1750027

2 (2017) 1750027

Yao, F., see Meng, D.

2 (2017) 1750027

Shi, C., Zhang, L., Mai, J. and Zhao, Z., 3D printing process selection model based on triangular intuitionistic fuzzy numbers in cloud manufacturing

Zhang, L., see Shi, C.

Mai, J., see Shi, C.

Zhao, Z., see Shi, C.

Xu, X., Ju, R., Liu, X., Li, G. and Son, Y.-J., Extending HTN to planning and execution control for small combat unit simulation

2 (2017) 1750032

$\mathrm{Ju}, \mathrm{R}$., see $\mathrm{Xu}, \mathrm{X}$.

2 (2017) 1750032

Liu, X., see $\mathrm{Xu}, \mathrm{X}$.

2 (2017) 1750032

Li, G., see Xu, X.

2 (2017) 1750032

Son, Y.-J., see Xu, X.

2 (2017) 1750032

Yaegashi, Y., Yoshioka, H., Unami, K. and Fujihara, M., An optimal management strategy for stochastic population dynamics of released Plecoglossus altivelis in rivers

2 (2017) 1750039

Yoshioka, H., see Yaegashi, Y.

Unami, K., see Yaegashi, Y.

2 (2017) 1750039

2 (2017) 1750039

Fujihara, M., see Yaegashi, Y.

2 (2017) 1750039

Qiao, L., Qie, Y. and Zhu, Y., Modeling for assembly simulations: Data description and a data-driven construction framework

Qie, Y., see Qiao, L.

2 (2017) 1750044

2 (2017) 1750044

Zhu, Y., see Qiao, L.

2 (2017) 1750044

Shen, Z., Guo, L., Hou, B., Quan, H. and Zhou, S., Key technique research on desktop virtualization in cloud environment

2 (2017) 1750045

Guo, L., see Shen, Z.

2 (2017) 1750045

Hou, B., see Shen, Z.

2 (2017) 1750045

Quan, H., see Shen, Z.

2 (2017) 1750045

Zhou, S., see Shen, Z.

2 (2017) 1750045

Hou, P., Pan, H. and Guo, C., Simulation research for mobile robot path planning based on improved artificial potential field method recommended by the AsiaSim 
Pan, H., see Hou, P.

Guo, C., see Hou, P.

Li, Y., Qiao, L., Khaleeq uz Zaman, U. and Siadat, A., Calculation and analysis of assembly clearance based on nonideal surface discrete data

Qiao, L., see Li, Y.

Khaleeq uz Zaman, U., see Li, Y.

Siadat, A., see Li, Y.

Feng, W.-J., Yin, C., Li, X.-B. and Li, L., A classification matching method for manufacturing resource in cloud manufacturing environment

Yin, C., see Feng, W.-J.

Li, X.-B., see Feng, W.-J.

Li, L., see Feng, W.-J.

Wang, X., Kang, F. and Gu, H., Automatic LOD selection using viewpoint entropy

Kang, F., see Wang, X.

$\mathrm{Gu}, \mathrm{H}$., see Wang, X.

Zou, C., Yin, Y., Liu, X. and Li, H., Visualization of oil spill at sea surface based on texture projection

Yin, Y., see Zou, C.

Liu, X., see Zou, C.

Li, H., see Zou, C.

Chen, Y.-C., Gao, X.-B. and Gao, M., Numerical simulation on rolling characteristics of canard-controlled rockets with a free-spinning tail

Gao, X.-B., see Chen, Y.-C.

Gao, M., see Chen, Y.-C.

Meenu, M., Guha, P. and Mishra, S., Coupled heat and moisture transfer of a single mung bean grain based on IR heating

Guha, P., see Meenu, M.

Mishra, S., see Meenu, M.

Hammami, F., Ben Mabrouk, S. and Mami, A., Numerical investigation of low relative humidity aeration impact on the moisture content of stored wheat

Ben Mabrouk, S., see Hammami, F.

Mami, A., see Hammami, F.

Lakoud, A., Curet, S. and Hassouna, M., Experimental investigation and numerical modeling of the hydration operation of date fruits

Curet, S., see Lakoud, A.
2 (2017) 1750046

2 (2017) 1750046

2 (2017) 1750050

2 (2017) 1750050

2 (2017) 1750050

2 (2017) 1750050

2 (2017) 1750057

2 (2017) 1750057

2 (2017) 1750057

2 (2017) 1750057

2 (2017) 1750059

2 (2017) 1750059

2 (2017) 1750059

2 (2017) 1750060

2 (2017) 1750060

2 (2017) 1750060

2 (2017) 1750060

2 (2017) 1750061

2 (2017) 1750061

2 (2017) 1750061

2 (2017) 1740001

2 (2017) 1740001

2 (2017) 1740001

2 (2017) 1740002

2 (2017) 1740002

2 (2017) 1740002

2 (2017) 1740003

2 (2017) 1740003 
Hassouna, M., see Lakoud, A.

$2(2017) 1740003$

Olaniyan, A. M., Adeoti, J. A. and Sunmonu, M. O., Effect of foaming agent, foam stabilizer and whipping time on drying process of tomato paste under different drying equipment

2 (2017) 1740004

Adeoti, J. A., see Olaniyan, A. M.

Sunmonu, M. O., see Olaniyan, A. M.

2 (2017) 1740004

2 (2017) 1740004

Zhao, C., Zhang, L., Liu, Y., Zhang, Z., Yang, G. and Li, B.

H., Agent-based simulation platform for cloud manufacturing

3 (2017) 1742001

Zhang, L., see Zhao, C.

3 (2017) 1742001

Liu, Y., see Zhao, C.

3 (2017) 1742001

Zhang, Z., see Zhao, C.

3 (2017) 1742001

Yang, G., see Zhao, C.

3 (2017) 1742001

Li, B. H., see Zhao, C.

3 (2017) 1742001

Wang, J., Liu, Q. and Zhai, X., A method for threshold selection in load extrapolation based on multiple criteria decision-making technology

Liu, Q., see Wang, J.

3 (2017) 1750019

3 (2017) 1750019

Zhai, X., see Wang, J.

3 (2017) 1750019

Deepu, M., Dhrishit, M. P. and Shyji, S., Numerical simulation of high speed reacting shear layers using $\mathrm{AUSM}^{+}$- up scheme-based unstructured finite volume method solver

3 (2017) 1750020

3 (2017) 1750020

Dhrishit, M. P., see Deepu, M.

Shyji, S., see Deepu, M.

3 (2017) 1750020

Karlekar, N. P. and Gomathi, N., Kronecker product and bat algorithm-based coefficient generation for privacy protection on cloud

3 (2017) 1750021

3 (2017) 1750021

Gomathi, N., see Karlekar, N. P.

3 (2017) 1750023 based on wavelet neural network

Jian, S., see Wen, X.

3 (2017) 1750023

Umair, S. M. and Gulhane, N. P., On numerical investigation of nonuniformity in cooling characteristic for different materials of target surfaces being exposed to impingement of air jet

3 (2017) 1750024

Gulhane, N. P., see Umair, S. M.

Li, M. and Huang, C., ADI Galerkin FEMs for the 2d nonlinear time-space fractional diffusion-wave equation 3 (2017) 1750024

Huang, C., see Li, M.

3 (2017) 1750025

3 (2017) 1750025 
Che, Z., Zhao, C., Laili, Y. and Zhang, L., Research on the dynamic management of cloud simulation derived data

3 (2017) 1750026

Zhao, C., see Che, Z.

3 (2017) 1750026

Laili, Y., see Che, Z.

3 (2017) 1750026

Zhang, L., see Che, Z.

Liu, J., Adaptive forgetting factor OS-ELM and bootstrap for time series prediction

3 (2017) 1750026

3 (2017) 1750029

Bouzid, L. and Belhamiti, O., Effect of seasonal changes on predictive model of bovine babesiosis transmission

Belhamiti, O., see Bouzid, L.

3 (2017) 1750030

3 (2017) 1750030

Wang, J. and Li, S., Modeling and simulation of network traffic flow evolution based on incomplete information feedback strategies in the ATIS environment

3 (2017) 1750031

3 (2017) 1750031

Xiao, J., Li, W. and Xiao, X., Improved clonal selection algorithm optimizing Neural Network for solving terminal anti-missile collaborative intercepting assistant decision-making model

3 (2017) 1750033

3 (2017) 1750033

3 (2017) 1750033

Xiao, X., see Xiao, J.

Aggoune, L. and Chetouani, Y., Modeling of a distillation column based on NARMAX and Hammerstein models

3 (2017) 1750034

3 (2017) 1750034

Chetouani, Y., see Aggoune, L.

Masouleh, M. F., Kazemi, M. A. A., Alborzi, M. and Eshlaghy, A. T., Identification of electrocardiogram signals using internet of things based on combinatory classification

3 (2017) 1750035

3 (2017) 1750035

3 (2017) 1750035

3 (2017) 1750035

Eshlaghy, A. T., see Masouleh, M. F.

Thomas, M. V. and Chandrasekaran, K., Dynamic partner selection in Cloud Federation for ensuring the quality of service for cloud consumers

3 (2017) 1750036

3 (2017) 1750036

Yang, D., Huang, J. and Zhao, W., A quasi-dynamic model

3 (2017) 1750037 and a symplectic algorithm of super slender Kirchhoff rod

Huang, J., see Yang, D.

Zhao, W., see Yang, D.

3 (2017) 1750037

3 (2017) 1750037

Tserpes, K. and Koumpias, A., Molecular mechanics-based finite element analysis of graphene sheet and carbon nanotubes using the rebo potential

3 (2017) 1750038

Koumpias, A., see Tserpes, K.

3 (2017) 1750038 
D'Ercole, R., Detecting the filamentary structure of 3D point clouds: Proposal of a wavelet-based method

Luo, C., Xu, K. and Zhao, Y., A TVD discretization method for shallow water equations: Numerical simulations of tailing dam break

3 (2017) 1850001

$\mathrm{Xu}, \mathrm{K}$., see Luo, C.

Zhao, Y., see Luo, C.

3 (2017) 1850001

3 (2017) 1850001

Papadopoli, N., ATC simulation for flight training: The missing link

4 (2017) 1743001

van der Wall, B. G. and Yin, J., A model for real-time computation of fuselage-rotor interference

Yin, J., see van der Wall, B. G.

Du Val, R. and He, C., FLIGHTLAB ${ }^{\mathrm{TM}}$ modeling for real-time simulation applications

He, C., see Du Val, R.

Jones, M., A method for automatic tuning of flight simulator motion platforms

4 (2017) 1743002

4 (2017) 1743002

4 (2017) 1743003

4 (2017) 1743003

$4(2017) 1743004$

Oruc, I., Horn, J. F., Shipman, J. and Polsky, S., Towards real-time pilot-in-the-loop CFD simulations of helicopter/ship dynamic interface

4 (2017) 1743005

Horn, J. F., see Oruc, I.

4 (2017) 1743005

4 (2017) 1743005

Shipman, J., see Oruc, I.

4 (2017) 1743005

Duan, J.-S. and Chen, Y., Mechanical response and simulation for constitutive equations with distributed order derivatives

4 (2017) 1750040

4 (2017) 1750040

Wan, F., Yin, Y., Zhang, Q. and Peng, X., Analysis of parallel multigrid methods in real-time fluid simulation

4 (2017) 1750042

4 (2017) 1750042

4 (2017) 1750042

4 (2017) 1750042

Peng, X., see Wan, F.

Gao, M., Zhou, L. and Chen, Y., Reliable optimization of corridor capacity for China high speed railway by considering passenger service

4 (2017) 1750043

4 (2017) 1750043

4 (2017) 1750043

Chen, Y., see Gao, M.

Kant, C. J. and Mayya, K. B. K., Simulation of the effect of quantum dot location on a quantum dot $p-i$ - $n$ junction solar cell

4 (2017) 1750047

Mayya, K. B. K., see Kant, C. J.

4 (2017) 1750047 
Zhou, B. and Xu, J., An adaptive SVM-based real-time scheduling mechanism and simulation for multiple-load carriers in automobile assembly lines

4 (2017) 1750048

$\mathrm{Xu}$, J., see Zhou, B.

4 (2017) 1750048

Wang, J., Liu, J., Wang, T. and Cheng, L., An efficient complex event detection model for high proportion disordered RFID event stream

4 (2017) 1750049

Liu, J., see Wang, J.

4 (2017) 1750049

Wang, T., see Wang, J.

4 (2017) 1750049

Cheng, L., see Wang, J.

4 (2017) 1750049

Matsuoka, D., Extraction, classification and visualization of 3-dimensional clouds simulated by cloud-resolving atmospheric model

4 (2017) 1750051

Zhou, Y., Ma, Y., Song, X. and Gong, G., Hierarchical fuzzy ART for Q-learning and its application in air combat simulation

4 (2017) 1750052

Ma, Y., see Zhou, Y.

4 (2017) 1750052

Song, X., see Zhou, Y.

4 (2017) 1750052

Gong, G., see Zhou, Y.

4 (2017) 1750052

Awais, M. U., Cvetkovic, M. and Palensky, P., Hybrid simulation using implicit solver coupling with HLA and FMI

4 (2017) 1750055

Cvetkovic, M., see Awais, M. U.

4 (2017) 1750055

Palensky, P., see Awais, M. U.

4 (2017) 1750055

Cufoglu, A., Lohi, M. and Everiss, C., Feature weighted clustering for user profiling

4 (2017) 1750056

Lohi, M., see Cufoglu, A.

4 (2017) 1750056

Everiss, C., see Cufoglu, A.

4 (2017) 1750056 